\title{
Modification of SPION Nanocarriers for Sirna Delivery: A Therapeutic Strategy Against HIV Infection
}

\author{
Iranpur Mobarakeh Vahid ${ }^{1}$, Modarressi Mohammad Hossein ${ }^{1,2}$, Rahimi Pooneh $^{3, *}$, Bolhassani Azam $^{3}$, Arefian Ehsan $^{4}$
}

\author{
${ }^{1}$ Department of Biology, School of Basic Sciences, Science and Research Branch, Islamic Azad University, Tehran, Iran; \\ ${ }^{2}$ Department of Medical Genetics, School of Medicine, Tehran University of Medical Sciences, Tehran, Iran; ${ }^{3}$ Department of \\ Hepatitis and AIDS, Pasteur Institute of Iran, Tehran, Iran; ${ }^{4}$ Department of Microbiology, School of Biology, College of Science, \\ University of Tehran, Tehran, Iran
}

\begin{tabular}{|c|c|}
\hline A R T ICLE IN FO & A B S T R A C T \\
\hline $\begin{array}{l}\text { Original Article } \\
\text { VacRes, 2019 } \\
\text { Vol 6, No.1, } 43 \text { - } 49 \\
\text { Received: December 20, } 2019 \\
\text { Accepted: February 02, } 2020 \\
\text { Pasteur Institute of Iran } \\
\text { *Corresponding Author: Dr. } \\
\text { Pooneh Rahimi, Pasteur Institute } \\
\text { of Iran, Tehran, Iran } \\
\text { Email: prahimi@ pasteur.ac.ir } \\
\text { Tel/Fax: +98 2166953323 } \\
\text { KEYWORDS: siRNA, Vaccine } \\
\text { Delivery, HIV-1 tat, SPION, } \\
\text { Chitosan }\end{array}$ & $\begin{array}{l}\text { Introduction: To date, while many studies have investigated antiviral agents or } \\
\text { vaccines against HIV, success has been limited. In this field, mutagenesis of the } \\
\text { viral genome mostly contributes to the viral escape from the antiretroviral } \\
\text { therapies as well as the emergence of resistant strains of HIV-1 to pharmaceutical } \\
\text { therapy. Therefore, developing alternative methods, including more effective } \\
\text { vaccines, antiviral therapies (such as RNAi therapy) and delivery systems, seem } \\
\text { to be necessary to compensate for these issues. The aim of this research was to } \\
\text { establish an efficient system for siRNA delivery as a safe anti-HIV therapeutic } \\
\text { approach. Methods: Chitosan-coated superparamagnetic iron oxide nanoparticles } \\
\text { (SPION) was investigated as a method for RNA delivery. After generating } \\
\text { HEK293 stable cells (expressing HIV-1 tat), a potent siRNA against HIV-1 tat } \\
\text { was designed and the effectiveness of the modified SPION in siRNA delivery to } \\
\text { HEK293 cells was evaluated. Results: The optimal concentration ( } 50 \mu \text { g/mL) of } \\
\text { the modified SPION-containing anti-tat siRNA (with a range size of } 50-70 \text { nm } \\
\text { and average zeta potential of + } 25 \mathrm{mV} \text { ) was significantly internalized into the cells } \\
\text { and decreased the expression of HIV-1 tat, more than } 80 \% \text {. Moreover, the } \\
\text { nanoparticles showed no considerable toxicity on the cells. Conclusion: SPION } \\
\text { could be optimized as a probable RNA/vaccine delivery system into target cells. } \\
\text { Therefore, this study offers a therapeutic strategy against HIV or other infectious } \\
\text { diseases. }\end{array}$ \\
\hline
\end{tabular}

\section{INTRODUCTION}

To date, antiviral therapeutics and vaccines have been successfully used against infectious diseases; however unfortunately, there is no currently approved vaccine or cure for human immunodeficiency virus (HIV)/AIDS [1]. HIV has unique ways of escaping the immune system, and it seems that the human body is incapable of presenting an effective immune response against it. As a result, developing alternative methods, including more effective vaccines and treatments, seem to be imperative to provide protection against HIV infection [2]. On the other hand, one of the important issues in a successful vaccination or antiviral therapy (such as RNAi therapy) is developing an efficient delivery system to protect the nucleic acids from the nuclease degradation, as well as to deliver and release the nucleic acids into the cells $[3,4,5]$. In this way, non-viral vectors have been shown to be more useful and safer alternatives compared to the viral vectors [3].

Superparamagnetic iron oxide nanoparticles (SPIONs) have attracted attention in nucleic acid delivery applications due to their low cost, low toxicity, and potential for direct targeting by using external magnets. Therefore, SPIONs could be used as both diagnostic and therapeutic agents because of their unique characteristics [6]. Moreover, the mechanism of magnetic hyperthermia of SPIONs can be applied to suppress the HIV viral load, since hyperthermic temperatures increase the activity of cytotoxic T lymphocytes (CTLs), which can inhibit HIV replication [7]. On the contrary, due to the nonreproducibility of synthesis and agglomeration of the SPION colloidal suspensions, their clinical use have been limited $[8,9]$. To tackle these issues, the SPION surface can be coated with synthetic or natural polymers such as polyethylene glycol, alginate, dextran, chitosan and polyethylenimine. Therefore in our study, the surface of SPION was coated with trimethyl chitosan (TMC) and polyethylenimine (PEI) to prevent the agglomeration and to enhance the solubility of SPION [7]. These polymers could also promote the cell uptake through condensation of nucleic acids (DNA or RNA) into nanoparticles [3].

TMC is a derivative of chitosan (a biocompatible and non-toxic polymer) that displays a positive charge and great water solubility in a broad range of $\mathrm{pH}$ [10]. The positive 
charge of TMC can enhance the loading quantity of nucleic acids into nanoparticles [7]. Moreover, PEI is the most efficient polymer for nucleic acid delivery due to its high capacity of proton-buffering; although it is dose-dependent toxic [11, 12]. Therefore, the combined use of PEI and chitosan with SPION could suggest a promising strategy to accomplish a highly effective nanocarrier with low cytotoxic effect.

In the present study, we aimed to establish an effective delivery system for siRNA (or other nucleic acids) as a safe anti-HIV therapeutic approach. Thus, after generating a stable cell line of HEK293 (to express HIV-1 tat), we designed a potent anti-tat siRNA, and then the effectiveness of our nanoparticle (SPION-TMC-PEI) in siRNA delivery to HEK293 cells was evaluated. The inhibition of tat RNA expression was also studied in the stable cells.

\section{MATERIALS and METHODS}

\section{Materials}

Fetal bovine serum (FBS), Dulbecco's modified Eagle's medium (DMEM), Opti-MEM medium and trypsin-EDTA were supplied by Gibco (NY, USA). Cell proliferation kit II (XTT) was purchased from Roche (Mannheim, Germany), and the other chemicals were provided from Sigma-Aldrich (MO, USA).

Generation of Stable Cells (Expressing HIV-1 tat)

HEK293 cell line was provided by the Pasteur Institute of Iran (Tehran, Iran) in order to create stable cells (expressing HIV-1 tat). The cells were seeded in DMEM containing 10\% FBS, $100 \mu \mathrm{g} / \mathrm{mL}$ of streptomycin (Biochrom, Germany), and $100 \mathrm{U} / \mathrm{mL}$ of penicillin (Biochrom, Germany). HIV-1 tat (GenBank accession number GQ473128.1) was synthesized by Biomatik Corporation (Ontario, Canada) and then subcloned into pEGFP-N1 vector (Clontech, USA; Fig. 1). The pEGFPN1-tat was transfected into the cells ( $70 \%$ confluent) using Lipofectamine 3000 reagent (Invitrogen, NY, USA), according to its manufacturer's protocol. The stable cells were finally derived from a single cell (by the method of limiting dilution), and the recombinant protein expression of Tat-GFP was verified through flow cytometry and qRT-PCR (data not shown)

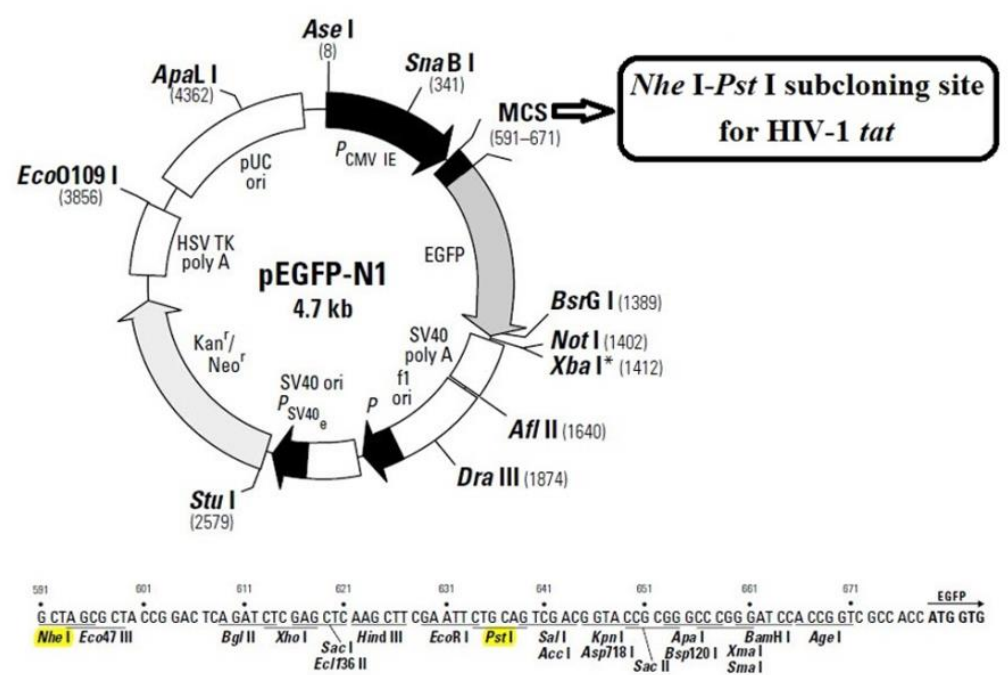

Fig. 1. Schematic illustration of pEGFP-N1 expression vector (GeneBank U55762). The HIV-1 tat gene was subcloned into the MCS (between two restriction enzymes Nhe I and Pst I).

\section{Preparation of SiRNA}

A total of 15 siRNAs to target HIV-1 tat, as well as a siRNA scrambled control, were designed by siDirect (http://sidirect2.rnai.jp/) and Oligo walk (http://rna.urmc.rochester.edu/cgi- bin/server_exe/oligowalk/oligowalk_form.cgi). Next, 3 siRNAs with higher scores, namely siRNA-63, siRNA-100 and siRNA102, were picked. All siRNAs were investigated for their thermodynamic properties [13]. Moreover, BLAST analyses were performed to avoid any non-specific effects of the siRNAs (Table 1).

Table 1. siRNA sequences against HIV-1 tat.

\begin{tabular}{|c|c|c|c|c|}
\hline Name & ${ }^{\text {a Position (bp) }}$ & Strand & Sequences $\left(5^{\prime}\right.$-> 3') & ${ }^{b}$ Modification \\
\hline \multirow{2}{*}{ siRNA-63 } & \multirow{2}{*}{$63-84$} & Sense & GUACCAAUUGUUAUUGUAAAA & none \\
\hline & & Antisense & UUACAAUAACAAUUGGUACAA & none \\
\hline \multirow{2}{*}{ siRNA-100 } & \multirow{2}{*}{$100-121$} & Sense & CCAAGUUUGUUUCAUAACAAA & none \\
\hline & & Antisense & UGUUAUGAAACAAACUUGGCA & none \\
\hline \multirow{2}{*}{ siRNA-102 } & \multirow{2}{*}{$102-122$} & Sense & CCAAGUUUGUUUCAUAACAA & none \\
\hline & & Antisense & UUGUUAUGAAACAAACUUGG & none \\
\hline \multirow{2}{*}{${ }^{\mathrm{c} S c r a m b l e d ~ s i R N A}$} & \multirow{2}{*}{-} & Sense & GCCGAUCUAAUCAGAGUUA & 3' TAMRA \\
\hline & & Antisense & UAACUCUGAUUAGAUCGGC & none \\
\hline
\end{tabular}

a Position of siRNA on the HIV-1 tat mRNA

b Fluorescently modification of siRNA strands

c Negative control of siRNA 
The scrambled siRNA (a negative control) was labeled with TAMRA dye (yellow) [3]. The selected siRNAs were manufactured by Bioneer Corporation (Daejeon, Korea). To determine the optimal siRNA (and its suitable concentration) and to inhibit the expression of HIV-1 tat, various concentrations of siRNAs were transfected in Opti-MEM medium, using the commercial reagent Lipofectamine RNAiMAX (Invitrogen, Karlsruhe, Germany) according to manufacturer's directions. The levels of gene expression were assessed through qRT-PCR assay (data not shown), and siRNA102 with a final concentration of $100 \mathrm{pmol} / \mathrm{mL}$ was selected as the most effective siRNA to prepare the nanoparticles.

\section{Preparation of Nanoparticles}

SPIONs were prepared through a co-precipitation approach [7]. In brief, $0.298 \mathrm{~g}$ of $\mathrm{FeCl}_{2} \cdot 4 \mathrm{H}_{2} \mathrm{O}$ and $0.810 \mathrm{~g}$ of $\mathrm{FeCl}_{3} \cdot 6 \mathrm{H}_{2} \mathrm{O}$ were dissolved in deionized water (in a nitrogen environment). Next, $25 \%$ (v/v) of ammonium hydroxide solution (as the size-controlling agent) was drop-wisely added at $70{ }^{\circ} \mathrm{C}$. The mixture was stirred for $1 \mathrm{~h}\left(\right.$ at $\left.70{ }^{\circ} \mathrm{C}\right)$ and then washed a few times through precipitation by a magnet and redispersion in water. The resulted SPIONs were dried at $40{ }^{\circ} \mathrm{C}$ in a vacuum oven. TMC was synthesized as described previously [14]. Briefly, $1 \mathrm{~g}$ of chitosan with $\mathrm{Mw}$ of $100-150 \mathrm{kDa}(95 \%$ deacetylation degree, Primex, Norway) was dissolved in $40 \mathrm{~mL}$ of N-methylpyrrolidone solvent (Merck, Germany), and then $2.4 \mathrm{~g}$ of sodium iodide (Merck, Germany) was dissolved into the mixture. Next, $6 \mathrm{~mL}$ of methyl iodide and $5.5 \mathrm{~mL}$ of $15 \%$ (w/v) sodium hydroxide solution (as the precursor) were added to the mixture and stirred at $2000 \mathrm{rpm}$ for $1 \mathrm{~h}\left(60^{\circ} \mathrm{C}\right)$. After adding $250 \mathrm{~mL}$ ethanol in order to separate the methylated chitosan, the mixture was centrifuged at 20,000 RCF (5 min). In order to dissolve the precipitated product, $20 \mathrm{~mL}$ of $10 \%$ (w/v) sodium chloride solution was added into the mixture. The solution was dialyzed for $24 \mathrm{~h}$ against deionized water (cut-off: $12 \mathrm{kDa}$ ) and then freeze-dried. TMC-coated SPIONs were finally provided by using electrostatic forces between anionic SPION and positively charged TMC. For this purpose, $5 \mathrm{mg}$ of the SPIONs were dispersed into $1 \mathrm{~mL}$ of deionized water and then sonicated for $30 \mathrm{~min}$ at room temperature (to create a homogeneous dispersion). The amount of $125 \mu \mathrm{l}$ of the TMC solution $(50 \mathrm{mg} / \mathrm{mL})$ was then added to the solution of SPIONs. After shaking for $24 \mathrm{~h}$ at room temperature, the TMC-covered SPIONs were separated by centrifugation for $15 \mathrm{~min}$ at 100,000 RCF. Herein, according to our experiment results, the N:P ratio (the molar ratio of polymer amine groups to siRNA phosphate groups) equals to 40 was shown to be the optimum ratio. Therefore, the optimal amounts of siRNA solution $(200 \mathrm{nM}$ of siRNA-102), PEI $25 \mathrm{kDa}$ solution $(15 \mu \mathrm{g} / \mathrm{mL})$ and SPIONTMC suspension $(50 \mu \mathrm{g} / \mathrm{mL})$ were added to deionized water, up to $500 \mu \mathrm{l}$ final volume in a $1.5 \mathrm{~mL}$ tube. The suspension was stirred for $40 \mathrm{~s}(2500 \mathrm{rpm})$ and then incubated for $60 \mathrm{~min}$ at room temperature. The size distribution and zeta potential of the nanoparticles were measured using DLS (dynamic light scattering).

Moreover, the nanoparticles surface morphology was evaluated by scanning electron spectroscopy (SEM, JEOLJSM-6700F, Japan).

\section{Gel Retardation Analysis}

The ability of the nanoparticles (SPION-TMC-PEI) to protect siRNA was investigated through gel retardation assay in a $2 \%$ agarose gel (for $45 \mathrm{~min}$ at $100 \mathrm{~V}$ ), and then siRNA was stained with 1X Gel Red (Biotium, USA). Naked siRNA was used as a control.

\section{Characterization of Nanoparticle Structure}

In order to investigate the dynamic surface processes of the optimal nanoparticle, their FTIR (Fourier transform infrared) spectra was measured by an FTIR spectrometer (Varian, California, USA). Here, samples were freeze-dried and mixed with potassium bromide $(\mathrm{KBr})$ to prepare pellets required for analysis of FTIR spectra.

\section{In Vitro Cytotoxicity Study}

The impact of various concentrations of the optimal nanoparticle on the viability of HEK293 cells was evaluated by using XTT method. In brief, $1 \times 10^{4}$ cells per well were cultured in a 96-well microplate in a volume of $100 \mu \mathrm{L}$ of DMEM with $10 \%$ FBS. The cells were incubated at $37^{\circ} \mathrm{C}$ for $24 \mathrm{~h}$ (with $5 \%$ $\mathrm{CO}_{2}$ ), and then the media were exchanged with culture media containing various concentrations of the optimal nanoparticle formulation (i.e. 10, 20, 50 and $100 \mu \mathrm{g} / \mathrm{mL}$ ). The cells were incubated at $37{ }^{\circ} \mathrm{C}$ for an additional $6 \mathrm{~h}$ under $5 \% \mathrm{CO}_{2}$ atmosphere, and the media were then exchanged with fresh media supplemented with $10 \%$ FBS. Cells were incubated for an additional $48 \mathrm{~h}$ at $37{ }^{\circ} \mathrm{C}$ in $5 \% \mathrm{CO}_{2}$. Herein, non-treated cells, cells treated with $100 \mathrm{pmol} / \mathrm{mL}$ of naked siRNA, and cells transfected with siRNA-Lipofectamine RNAiMAX (following the manufacturer's protocol) were used as controls. The fluorescence intensity of the cells was measured at the wavelength of $450 \mathrm{~nm}$ (with a $630 \mathrm{~nm}$ reference wavelength), using a micro-plate reader (Bio-Rad, USA). The samples in the experiment were in triplicate, and the results were indicated as the average values \pm standard deviation.

\section{Nanoparticles Cellular Uptake}

The cellular uptake of the optimal nanoparticles was monitored by Nikon confocal microscope A1 (Nikon Inc., Japan). HEK293 cells were seeded for $24 \mathrm{~h}$ at $5 \times 10^{5}$ cells per well on coverslips in 6-well plates, then washed and treated with nanoparticles labeled with TAMRA in media supplemented with $20 \% \mathrm{FBS}$ at $37{ }^{\circ} \mathrm{C}$ for $6 \mathrm{~h}$. After washing and fixation in $4 \%$ paraformaldehyde (for $10 \mathrm{~min}$ ), the cells were stained with Hoechst 33342 and observed under a confocal microscope.

\section{qRT-PCR Examination of HIV-1 tat Expression}

HIV-1 tat mRNA expression was investigated by SYBR Green qRT-PCR (quantitative real-time PCR). The stable HEK293 cells capable of expressing HIV-1 tat were cultured at a density of $2 \times 10^{5}$ cells per well on 6-well plates, and then were incubated in DMEM for $24 \mathrm{~h}$. The cell media were replaced by the various concentrations of optimal nanoparticle (i.e. 10, 20, 50 and $100 \mu \mathrm{g} / \mathrm{mL}$ ) in DMEM supplemented with $20 \%$ FBS. Cells treated with the scrambled siRNA $(100 \mathrm{pmol} / \mathrm{mL})$, and cells treated with $100 \mathrm{pmol} / \mathrm{mL}$ of naked siRNA, as well as cells transfected with siRNA-Lipofectamine RNAiMAX (following the manufacturer's protocol) were considered as controls. The cells were incubated at $37{ }^{\circ} \mathrm{C}$ for $6 \mathrm{~h}$ in a $5 \% \mathrm{CO}_{2}$ and then the media were replaced by fresh DMEM with $10 \%$ FBS. Next, the cells were incubated for an additional $48 \mathrm{~h}$ at 37 ${ }^{\circ} \mathrm{C}\left(5 \% \mathrm{CO}_{2}\right)$. Using a cDNA synthesis kit (Yekta Tajhiz Azma, Iran), the total RNA (extracted from the cells) was reversetranscribed, and the HIV-1 tat mRNA expression was measured by qRT-PCR assay. The mRNA expression was normalized for HPRT1 expression. The sequences of primers for PCR amplification of HIV-1 tat were designed as follows: 5'-CAAAAGGCTTAGGCATCTCC-3' and 5'-CTCCACCTTCTCCTTCGATT-3' for forward and reverse primers, respectively. In addition, the forward and reverse primers for HPRT1 PCR amplification were respectively: 
5'-GCTTGCTGGTGAAAAGGACCTCTCGAAG-3' and 5'-CCCTGAAGTACTCATTATAGTCAAGGGCAT-3', obtained from a reference [3]. All samples were in triplicate and the results were indicated as the average values \pm standard deviation.

\section{Statistical analyses}

Statistical analyses was carried out by the paired t test and ANOVA. The results were measured as mean \pm standard deviation (SD), and differences at $\mathrm{p}<0.05$ were considered as significant.

\section{RESULTS}

\section{Analysis of Particle Size and Zeta Potential}

The size of optimal nanoparticles (SPION-TMC-PEI), as determined by DLS, was between 70 and $90 \mathrm{~nm}$ (Fig. 2a), and the nanoparticles' zeta potential was about $+25 \mathrm{mV}$ (Fig. 2b). Moreover, the SEM image revealed that the optimal nanoparticles were spherical in shape with diameters roughly between 50 and $70 \mathrm{~nm}$ (Fig. 2c).
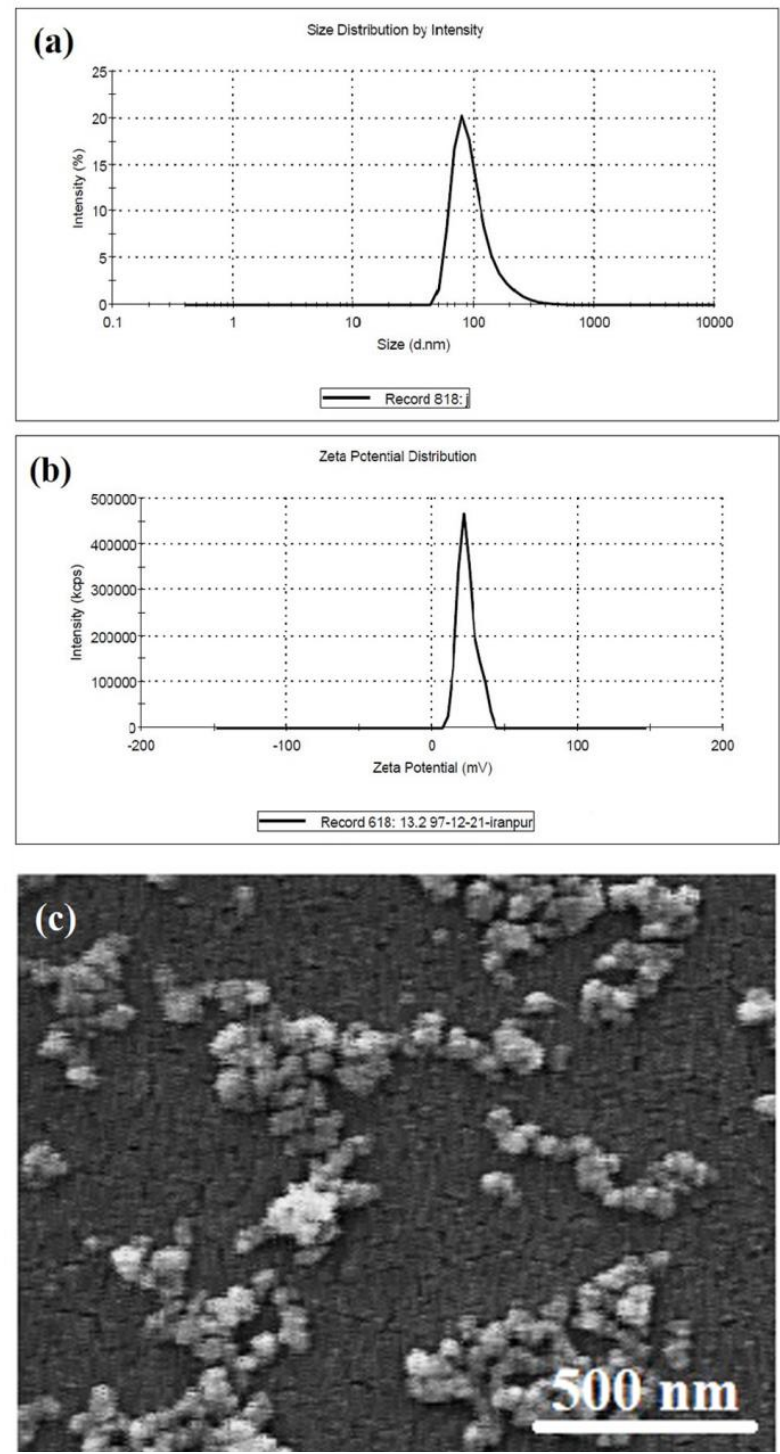

Fig. 2. Nanoparticles size and zeta potential. (a) Size distribution by intensity, measured by DLS, (b) Zeta potential distribution measured by DLS (c) SEM image of the optimal nanoparticles (SPION-TMC-PEI).

\section{Gel Retardation Analysis}

The results of gel retardation assay showed that the optimal nanoparticles (SPION-TMC-PEI) could retard siRNA

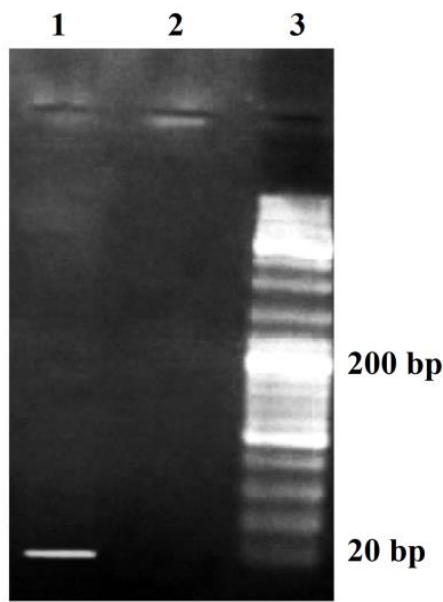

Fig. 3. Agarose gel retardation assay. Lane 1: naked siRNA (control), lane 2: siRNA-loaded nanoparticle, lane 3: RNA marker.

completely (Fig. 3).

\section{Analyses of Nanoparticles' Structure}

The FTIR spectra in the wavenumber range from 4000 to $400 \mathrm{~cm}^{-1}$ verified the formation of nanoparticles. The $\mathrm{Fe}-\mathrm{O}$ stretch band was observed in $598 \mathrm{~cm}^{-1}$ in spectra of SPION and SPION-TMC-PEI. In addition, the TMC and PEI characteristic peaks were observed in the nanoparticles which approved the successful coating of SPION with TMC and PEI (Fig. 4).

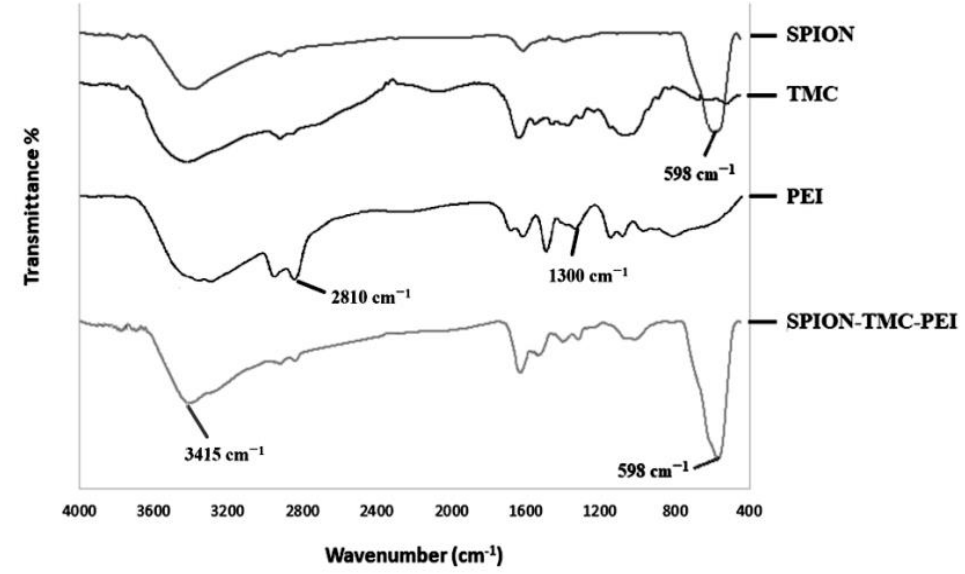

Fig. 4. FTIR spectra of the nanoparticle formulation.

\section{Evaluation of Cytotoxicity of Nanoparticles}

As shown in Fig. 6a, in group siRNA-loaded nanoparticles $(100 \mu \mathrm{g} / \mathrm{mL})$, the cell viability significantly ( $\mathrm{p}<$ 0.05 ) decreased (to $61 \%$ ) in comparison to that of the lower nanoparticle concentrations (i.e., 92,88 and $85 \%$ cell viability for the nanoparticle concentrations of 10,20 and $50 \mu \mathrm{g} / \mathrm{mL}$, respectively). In addition, at the concentration of $50 \mu \mathrm{g} / \mathrm{mL}$, the cell viability $(>85 \%)$ was not significantly $(p=0.47)$ different from transfected cells with the commercial reagent siRNALipofectamine RNAiMAX (with a cell viability of $81 \%$ ). Therefore, $50 \mu \mathrm{g} / \mathrm{mL}$ of the nanoparticle was used for cell uptake experiments. 


\section{Cellular Uptake Evaluation}

Evaluation of cellular uptake (in HEK293 cells) revealed a high uptake of TAMRA-labeled siRNA at the concentration

a

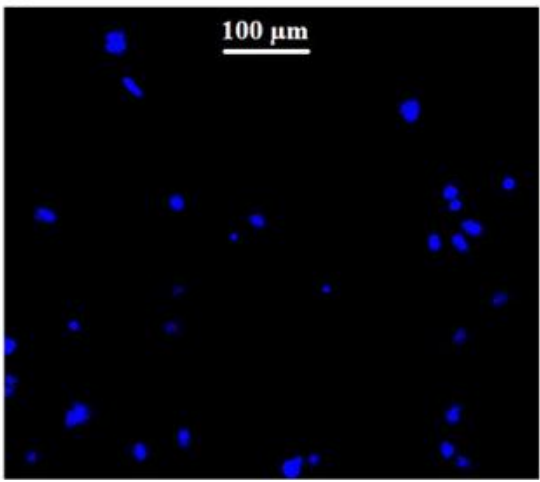

b

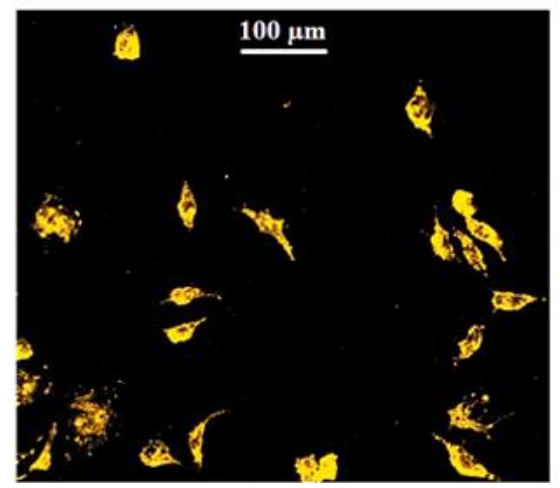

of $50 \mu \mathrm{g} / \mathrm{mL}$ of the optimal nanoparticle (Fig. 5). In contrast, the cells treated with naked TAMRA-labeled siRNAs showed very low cellular uptake (data not shown).

Fig. 5. Confocal microscopy images of HEK293 cellular uptake of TAMRA-labeled nanoparticles. (a) Cell nuclei stained with Hoechst 33342 dye (blue); (b) Cells treated with TAMRA-labeled nanoparticles (orange); (c) The merged image of the two fluorochromes used.

\section{Gene Expression Evaluation}

Fig. 6b indicates the tat mRNA expression in stable HEK293 cells after $48 \mathrm{~h}$ incubation with various treatment groups. The mRNA expression was down-regulated significantly in all groups of siRNA-loaded nanoparticles at various concentrations (i.e. 10, 20, 50 and $100 \mu \mathrm{g} / \mathrm{mL}$ ), c

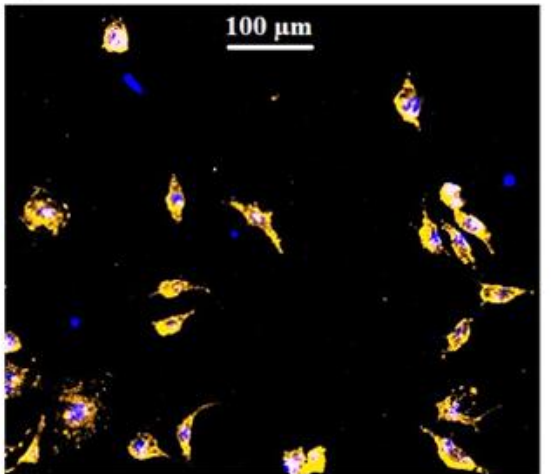

(a)

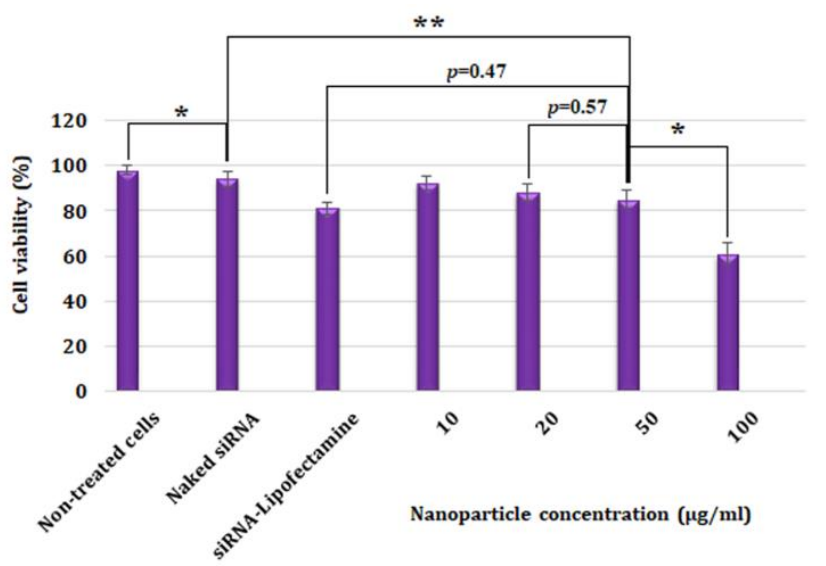

(b)

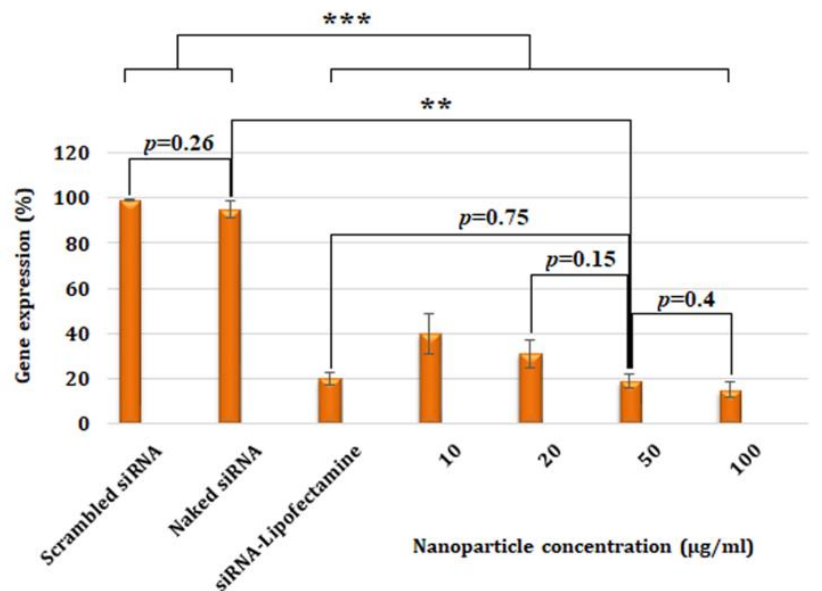

Fig. 6. The effect of various concentrations of the optimal nanoparticle (in comparison to the control groups) on (a) HEK293 cell viability and (b) HIV -1 tat expression. The results are indicated as mean values $\pm \operatorname{SD}(n=3)$. Statistical significances were determined as $\mathrm{p}<0.05, \mathrm{p}<0.01$ and $\mathrm{p}<0.001$. Anti-tat siRNA-Lipofectamine RNAiMAX was utilized as a positive control. 


\section{DISCUSSION}

The main goal of this research was to develop a SPIONbased RNA delivery system into cells because of the remarkable properties of SPIONs that can be applied in HIV treatment.

SPIONs were covered by two polymers (PEI and TMC) to obtain a stable and effective drug/ vaccine delivery nanocarrier system. In the literature, both polymers used here have indicated high potential for delivery of nucleic acids (DNA or RNA) into various cell types and have facilitated cell uptake by compacting nucleic acids into nanoparticles [7, 15]. Furthermore, they are shown to protect nucleic acids from degradation caused by extracellular enzymes, and also could help nucleic acids escape from endolysosomes [10].

Herein, the results of FTIR spectroscopy verified the formation of SPION-TMC-PEI. Moreover, according to our results (data not shown), the $\mathrm{N}: \mathrm{P}$ ratio of 40 was considered to be the optimal ratio due to the appropriate size and positive zeta potential and also the high efficiency of RNA loading. It has been shown that the particle size below $150 \mathrm{~nm}$ together with a modest positive zeta potential are important for an effective cell uptake [7]. The positive surface charge of the nanoparticles can increase their stability and protects the nanoparticles from aggregation [16]. In addition, the positively-charged nanoparticles can efficiently interact with the negativelycharged plasma membrane of the cells, enhancing the uptake of the nanoparticles into the cells [17].

As shown in Figure 3, the optimal nanoparticles (SPIONTMC-PEI) could efficiently retard the siRNA. This indicates that the positively-charged PEI and TMC in the nanoparticles structure have an important role in siRNA condensation into the nanoparticles. Moreover, the SEM image revealed the spherical shape and dispersed distribution of the optimal nanoparticles. The XTT assay (Fig. 6a) confirmed an acceptable low-toxicity of the optimal nanoparticle. The results indicated that the viability of cells treated with PEI-TMC-SPIONs were significantly different from the cells treated with naked siRNA. However, the cells transfected with the concentrations $\leq 50$ $\mu \mathrm{g} / \mathrm{mL}$ of the nanoparticle showed cell viability of more than $80 \%$, indicating a tolerable biocompatibility of the optimal nanoparticle at this concentration. Previous researches have also reported the biocompatibility and safety of SPIONs $[7,18]$.

The optimum formulation of SPION-TMC-PEI showed an effective cellular uptake. It has to be noticed that here the cell line HEK293 was used to generate the stable cells because of its simplicity to create stable cells and also its high gene expression. This provided a safer and easier approach to investigate the efficiency of the nanoparticles, compared to directly working with HIV-1 infected cells. Furthermore, the investigation of the cell transfection and gene silencing were accomplished in the medium supplemented by serum, implying the nanoparticle stability. The results of qRT-PCR analysis (Fig. 6b) indicated that the siRNA-loaded SPION-TMC-PEI $(50 \mu \mathrm{g} / \mathrm{mL}$ of nanoparticle with a dose of $100 \mathrm{pmol} / \mathrm{mL}$ of siRNA) increased the siRNA quantity into the cells and thus dramatically decreased the expression of HIV-1 tat gene in comparison with the controls (i.e. cells transfected with Lipofectamine RNAiMAX containing scrambled siRNA (100 $\mathrm{pmol} / \mathrm{mL}$ ) and also cells treated with $100 \mathrm{pmol} / \mathrm{mL}$ of naked anti-tat siRNA; $\mathrm{p}<0.001)$. Furthermore, the gene expression in the cells treated with $50 \mu \mathrm{g} / \mathrm{mL}$ of the nanoparticles was as low as that of the cells transfected with siRNA-Lipofectamine RNAiMAX which indicated the high efficiency of the optimal nanoparticles at this concentration to inhibit the gene expression. Therefore, considering the significant cytotoxicity of the nanoparticles at the concentration of $100 \mu \mathrm{g} / \mathrm{mL}$ (Fig. 6a) compared with that of $50 \mu \mathrm{g} / \mathrm{mL}$ ( $<<0.05$ ), the $50 \mu \mathrm{g} / \mathrm{mL}$ of SPION-TMC-PEI nanocarrier was presented as the optimal concentration to deliver siRNA into the target cells. It has to be noticed that the stable cells (expressing HIV-1 Tat protein) were only used to investigate the gene silencing while other methods of analysis, such as cell uptake, were achieved on unstable cells. This was because Tat as a transducing protein could affect the cellular uptake mechanism [3].

In conclusion, the focus in this study was to evaluate the nanoparticle efficiency for delivering anti-tat siRNA into target cells and silencing HIV-1 tat (a critical viral regulatory gene). It is envisaged that SION-TMC-PEI formulations could be evaluated as an inexpensive and promising delivery system in preclinical and clinical research against HIV infection. However, the effectiveness of the nanoparticle to deliver other therapeutic nucleic acids such as vaccines against HIV require further investigations.

\section{ACKNOWLEDGEMENT}

This research was supported by the Institute Pasteur of Iran (grant number 771). The authors acknowledge the colleagues at Department of Hepatitis and AIDS of Pasteur Institute of Iran and Department of Pharmaceutics of Tehran University of Medical Sciences. We also would like to express our appreciation to Dr. Farnaz Sadat Mirzazadeh Tekie, as well as Dr. Maliheh Ramezanali, for their technical supports.

\section{CONFLICT OF INTEREST}

The authors report no conflicts of interest.

\section{REFERENCES}

1. Ho J, Al-Deen FMN, Al-Abboodi A, Selomulya C, Xiang SD, Plebanski $\mathrm{M}$ et al. $\mathrm{N}, \mathrm{N}^{\prime}$-Carbonyldiimidazole-mediated functionalization of superparamagnetic nanoparticles as vaccine carrier. Colloids and Surfaces B: Biointerfaces. 2011;83(1):83-90. doi.org/10.1016/j.colsurfb.2010.11.001. 2. Swamy $\mathrm{MN}$, Wu H, Shankar P. Recent advances in RNAi-based strategies for therapy and prevention of HIV-1/AIDS. Advanced drug delivery reviews. 2016;103:174-86. doi.org/10.1016/j.addr.2016.03.005.

3. Iranpur Mobarakeh V, Modarressi MH, Rahimi P, Bolhassani A, Arefian E, Atyabi F et al. Optimization of chitosan nanoparticles as an anti-HIV siRNA delivery vehicle. International journal of biological macromolecules. 2019;129:305-15. doi.org/10.1016/j.ijbiomac.2019.02.036.

4. Tang T, Weng T, Jia H, Luo S, Xu Y, Li L et al. Harnessing the layer-bylayer assembly technique to design biomaterials vaccines for immune modulation in translational applications. Biomaterials science. 2019;7(3):715-32. doi: 10.1039/C8BM01219A.

5. Haladjova E, Halacheva S, Momekova D, Moskova-Doumanova V, Topouzova-Hristova T, Mladenova K et al. Polyplex Particles Based on Comb-Like Polyethylenimine/Poly (2-ethyl-2-oxazoline) Copolymers: Relating Biological Performance with Morphology and Structure. Macromolecular bioscience. 2018;18(4):1700349. doi.org/10.1002/mabi.201700349.

6. Al-Deen FN, Selomulya C, Ma C, Coppel RL. Superparamagnetic nanoparticle delivery of DNA vaccine. DNA Vaccines. Springer; 2014. p. 181-94. doi: 10.1007/978-1-4939-0410-5 12.

7. Kamalzare S, Noormohammadi Z, Rahimi P, Atyabi F, Irani S, Tekie FSM et al. Carboxymethyl dextran-trimethyl chitosan coated superparamagnetic iron oxide nanoparticles: An effective siRNA delivery system for HIV-1 Nef. Journal of cellular physiology. 2019. doi.org/10.1002/jcp. 28655 .

8. Sharifi S, Seyednejad H, Laurent S, Atyabi F, Saei AA, Mahmoudi M. Superparamagnetic iron oxide nanoparticles for in vivo molecular and cellular imaging. Contrast media \& molecular imaging. 2015;10(5):329-55. doi.org/10.1002/cmmi.1638.

9. Mahapatro A, Singh DK. Biodegradable nanoparticles are excellent vehicle for site directed in-vivo delivery of drugs and vaccines. Journal of 
nanobiotechnology. 2011;9(1):55. doi.org/10.1186/1477-3155-9-55.

10. Nimesh S, Gupta N, Chandra R. Cationic polymer based nanocarriers for delivery of therapeutic nucleic acids. Journal of biomedical nanotechnology. 2011;7(4):504-20. doi.org/10.1166/jbn.2011.1313.

11. Messaoudi K, Clavreul A, Lagarce F. Toward an effective strategy in glioblastoma treatment. Part II: RNA interference as a promising way to sensitize glioblastomas to temozolomide. Drug discovery today. 2015;20(6):772-9. doi.org/10.1016/j.drudis.2015.02.014.

12. Kunath K, von Harpe A, Fischer D, Petersen H, Bickel U, Voigt K et al. Low-molecular-weight polyethylenimine as a non-viral vector for DNA delivery: comparison of physicochemical properties, transfection efficiency and in vivo distribution with high-molecular-weight polyethylenimine. Journal of Controlled Release. 2003;89(1):113-25. doi.org/10.1016/S01683659(03)00076-2.

13. Fakhr E, Zare F, Teimoori-Toolabi L. Precise and efficient siRNA design: a key point in competent gene silencing. Cancer gene therapy. 2016;23(4):73. doi.org/10.1038/cgt.2016.4.

14. Hamman J, Kotze A. Effect of the type of base and number of reaction steps on the degree of quaternization and molecular weight of N-trimethyl chitosan chloride. Drug development and industrial pharmacy. 2001;27(5):373-80. doi.org/10.1081/DDC-100104312.

15. Yang $Z$, Duan J, Wang J, Liu Q, Shang $R$, Yang $X$ et al Superparamagnetic iron oxide nanoparticles modified with polyethylenimine and galactose for siRNA targeted delivery in hepatocellular carcinoma therapy. International journal of nanomedicine. 2018;13:1851. doi:10.2147/IJN.S155537.

16. Berg JM, Romoser A, Banerjee N, Zebda R, Sayes CM. The relationship between $\mathrm{pH}$ and zeta potential of $\sim 30 \mathrm{~nm}$ metal oxide nanoparticle suspensions relevant to in vitro toxicological evaluations. Nanotoxicology. 2009;3(4):276-83. doi.org/10.3109/17435390903276941.

17. Seil JT, Webster TJ. Antimicrobial applications of nanotechnology: methods and literature. International journal of nanomedicine. 2012;7:2767. doi:10.2147/IJN.S24805.

18. Lindemann A, Pries R, Lüdtke-Buzug K, Wollenberg B. Biological properties of superparamagnetic iron oxide nanoparticles. IEEE Transactions on Magnetics. 2015;51(2):1-4. doi:10.1109/TMAG.2014.235825. 